Service social

\title{
Les idées politiques de Platon à Marx, par Michel Duquette et Diane Lamoureux, Montréal, Les Presses de l'Université de Montréal, 1993, 480 pages.
}

\section{Fatou Sarr}

Volume 42, numéro 3, 1993

Perspectives théoriques

URI : https://id.erudit.org/iderudit/706635ar

DOI : https://doi.org/10.7202/706635ar

Aller au sommaire du numéro

Éditeur(s)

École de service social de l'Université Laval

ISSN

1708-1734 (numérique)

Découvrir la revue

Citer ce compte rendu

Sarr, F. (1993). Compte rendu de [Les idées politiques de Platon à Marx, par Michel Duquette et Diane Lamoureux, Montréal, Les Presses de l’Université de Montréal, 1993, 480 pages.] Service social, 42(3), 151-153.

https://doi.org/10.7202/706635ar d'utilisation que vous pouvez consulter en ligne.

https://apropos.erudit.org/fr/usagers/politique-dutilisation/ 


\section{RECENSIONS}

\section{Les IDÉES POLITIQUes de PLATON À MARX}

\section{Michel Duquette et Diane Lamoureux}

Montréal, Les Presses de l'Université de Montréal, 1993, 480 pages.

Le thème central de l'ouvrage de Duquette et Lamoureux tourne autour de la question de la liberté de la personne humaine et des modes d'organisation politique que l'on juge les plus appropriés à la réalisation de cette liberté. Les auteurs abordent la question de la relation entre I'individu et la société, mais aussi de celle des êtres humains à la nature, ce qui mène à réfléchir sur les institutions. Ils se limitent à retenir les principaux courants qui ont marqué les tentatives de traduction des principes de justice et d'organisation sociale. Ils cherchent à relier les unes aux autres les différentes écoles de pensée pour montrer la relative cohérence et la relative continuité dans I'histoire de la pensée politique occidentale. Cette étude ne veut prendre en considération que l'histoire de la pensée occidentale.

L'ouvrage reprend la distinction classique entre l'Antiquité, le Moyen Âge, le XIXe siècle et les temps modernes. Il se divise en cinq parties qui respectent l'ordre chronologique tout en affichant une présentation thématique. Chaque partie est organisée autour $d^{\prime} u n$ thème central qui illustre le contexte culturel politique de chacune des périodes.

Le premier chapitre porte sur l'individu et la citoyenneté. II s'intéresse aux idées développées par les principaux auteurs de la Grèce antique, en particulier Platon et Aristote. Cette époque est caractérisée par deux moments: il se produit d'abord une effervescence de la philosophie politique, ensuite, avec le retrait du politique, se développe une ouverture à la culture personnelle de l'individu. Le thème de la citoyenneté soulève la question du pouvoir politique: est-il issu de la seule volonté d'une personne, de la collectivité, d'un groupe d'intérêt dominant, d'un pouvoir divin ou du droit et de la constitution? 
La deuxième partie concerne la Cité romaine qui, dès son apparition, était en contact avec la culture grecque, qui a donné naissance à la culture latine et imprégné fortement la culture occidentale.

La troisième partie porte sur le spirituel et le temporel, nous donne la mesure du débat principal du Moyen Âge occidental entre pouvoir spirituel et temporel. À la fin de l'Antiquité, le pouvoir politique n'est plus représentatif. Les institutions sont retournées au domaine du privé après avoir relevé de l'État pendant les grands siècles de l'Empire romain; et l'Église prend le relais du gouvernement civil dans la réalisation de certaines missions comme l'éducation.

La quatrième partie porte sur l'État moderne. À travers des auteurs comme Machiavel, Hobbes ou Montesquieu, Michel Duquette et Diane Lamoureux montrent l'ascension de la science politique moderne, qui pose une nouvelle conception du droit et de la politique autour du thème "la fondation de l'État moderne». Deux courants de pensée issus tous deux de la tradition grecque se développent parallèlement et s'opposent:

1. Un humanisme qui se veut d'abord un retour aux Anciens renoue avec le passé et redécouvre son héritage grec et romain. L'humanisme de la Renaissance, pour sa part, place l'être humain au cœur de sa réflexion et considère l'individu comme porteur de droit et sujet agissant dans l'univers politique.

2. Les théories de la souveraineté qui visent à conférer un pouvoir absolu au monarque prendront appui aussi sur la tradition héritée de l'Antiquité. Le travail de conceptualisation qui s'effectue entre la fin du Moyen Âge et les grandes révolutions de la fin du XVIII siècle s'articulent autour de la notion de souveraineté et de droits individuels.

La cinquième partie, qui a pour thème "Liberté, égalité et révolutions", traite de l'émergence du monde contemporain et des systèmes politiques. Contrairement aux autres parties, les références ne portent pas sur des auteurs, mais plutôt sur des courants de pensée. Chaque courant sera brièvement développé (conservateurs, libéraux, socialistes, anarchistes et existentialistes). Le marxisme est devenu une province de la pensée occidentale. Face au péril socialiste, le libéralisme et le conservatisme divisés par une haine séculaire ont fini par s'allier, mais ne se sont jamais confondus. Le travail se termine par un survol de la pensée politique au $X X^{\mathrm{e}}$ siècle, qui va devoir faire face à un phénomène nouveau: le totalitarisme.

En conclusion, les auteurs disent que c'est au nom de la raison instrumentale que l'Occident en est arrivé à une gestion désastreuse des institutions et des écosystèmes, et cela justifie l'importance d'une interrogation philosophique sur la politique. À cause du déclin des idéologies politiques et de la crise des modèles de transformation sociale, la philosophie politique, en déclin au $\mathrm{XX}^{\mathrm{e}}$ siècle, commence à relever la tête. 
Les idées politiques de Platon à Marx est un manuel scolaire et la dimension du problème qu'il veut couvrir donne une idée de la tâche ardue, mais passionnante qui attend le lecteur. L'ouvrage est très accessible et le choix d'inclure de larges fragments de textes, loin d'alourdir la démarche, révèle au contraire une perspective fort intéressante qui facilite l'accès aux auteurs anciens. La question individu / société est au cœur du débat en service social, et cet ouvrage permet de situer les fondements philosophiques du système de pensée occidental qui a donné naissance aux politiques sociales actuelles.

Malgré la volonté déclarée dès le départ de se limiter au monde occidental, les auteurs ont présenté des textes sur l'islam et la philosophie politique. Ils font une analyse assez partielle de la pensée des auteurs comme Avorroés et Al Fabari, ne retenant que l'influence d'Aristote sur ces derniers, comme si I'on pouvait exclure tout I'héritage culturel islamique. Cela relance le débat sur l'influence de la culture arabe sur la Grèce, fondatrice de la civilisation occidentale.

En refermant ce livre, on a l'impression que l'histoire de la pensée occidentale depuis Platon est d'une remarquable continuité dans le sujet de ses angoisses et de ses interrogations: liberté, égalité, justice.

Fatou SARR

Étudiante au doctorat en service social Université Laval

\section{Histoire de la SÉCURItÉ SOCIALE AU CANADA (version française)}

\section{Dennis Guest}

Québec, Les Éditions du Boréal, 1993, 475 pages.

Édition originale anglaise publiée en 1980 sous le titre The Emergence of Social Security in Canada, Presses de I'Université de la Colombie-Britannique.

Comme l'annonce le feuillet publicitaire, il s'agit de la première histoire complète du système de la sécurité sociale, de l'époque coloniale jusqu'à aujourd'hui. Dans cette édition mise à jour, Dennis Guest décrit les changements survenus dans l'économie et les politiques sociales jusqu'au défunt Accord de Charlottetown.

Le livre se compose de 14 chapitres.

Les principaux thèmes abordés dans le premier chapitre sont la conception résiduelle et la conception institutionnelle de la sécurité sociale, le minimum social, les causes de la pauvreté et de la dépendance, 